\title{
Design of pipelines for high operating pressure by numerical simulations and experimental validation
}

\author{
Y. Theiner, H. Lehar \& G. Hofstetter \\ Institute for Basic Sciences in Civil Engineering, \\ University of Innsbruck, Austria
}

\begin{abstract}
For pipelines laid in difficult ground, as frequently encountered in Alpine regions, a pipe system, consisting of individual pipes, made of ductile cast iron, which are connected at joints at the construction site, are a favourable type of construction. The paper deals with the development of such pipelines for high operating pressures. Because the joints have to sustain both the high operating pressure and high axial forces assuring water tightness, they are a critical part of such pipelines. In this contribution the synthesis of numerical simulations and experimental validation will be presented as an efficient approach for developing such pipes. The dimensions of prototypes are determined on the basis of the results of fully three-dimensional FE-simulations. These prototypes are then used to check the design by ultimate load testes and to compare the numerical prediction with the measured response.

Keywords: penstock, pipelines, high operating pressure, ductile cast iron, sleeve joints, numerical simulation, material and geometric nonlinear behaviour, contact behaviour, load carrying behaviour, experimental validation.
\end{abstract}

\section{Introduction}

In Alpine regions, frequently difficult ground conditions are encountered for the laying of pipelines. A suitable construction type for difficult terrain is a pipe system, consisting of individual pipes made of ductile cast iron, which are connected at joints at the construction site. 
The flexibility of the joints allows an easy adaptation of the course of the pipeline to irregular ground conditions, like bends in the trench (Figure 1). In the present case pipes of five meter length are connected at a joint by locking bars and water tightness is assured by a rubber sealing (Figure 2). There exists a broad range of applications for such pipelines including water supply lines for drinking water, for artificial snow machines [1] and for fire fighting services as well as penstocks for hydro power plants [2].

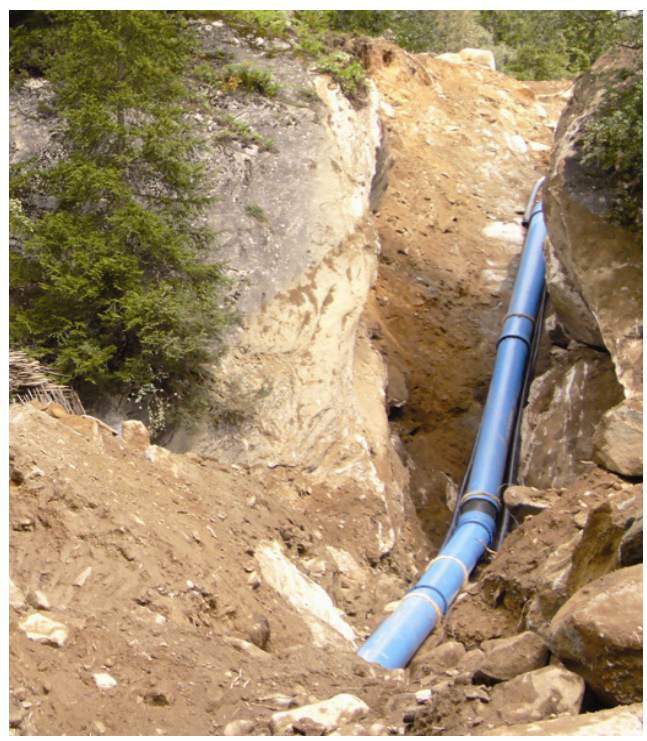

Figure 1: $\quad$ Laying of pipes in Alpine regions.

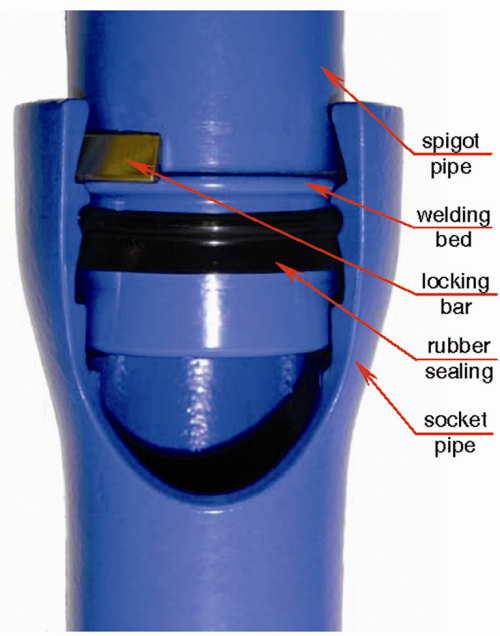

Figure 2: Connection of two adjacent pipes. 
In collaboration with the Austrian company Duktus - Tiroler Rohrsysteme $\mathrm{GmbH}$ and the Unit of Strength of Materials and Structural Analysis of the University of Innsbruck, such pipelines are developed with the aims (i) to allow high operating pressures, (ii) to minimise material requirements, (iii) to develop geometric properties of the sleeve joints, allowing for an easy application of coatings and (iv) to permit simple connections of adjacent pipes at the construction site. The collaborative research project was funded by the Austrian Research Promotion Agency (FFG). This project follows a previous project on the development of pile-supported buried pipelines for sewage disposal at atmospheric internal pressure in regions with poor soil conditions $[3,4]$.

The aim of the present paper is to describe the employed approach for developing pipe systems for high operating pressures. The design approach is characterized by a synthesis of numerical and experimental investigations. The described pipe systems are developed for a large range of different diameters and wall thicknesses. For brevity, this paper exemplarily focuses on a particular pipeline, classified as DN 200 K13 according to the European standard ÖNORM EN 545 [5]. It is characterized by a pipe diameter of $200 \mathrm{~mm}$ and a wall thickness of $9.1 \mathrm{~mm}$. The intended operating pressure is $100 \mathrm{bar}$.

\section{Numerical model}

The joints are the critical regions of such pipelines. Hence, it is important to properly reflect the behaviour of the connection of two adjacent pipes in a numerical model. In order to comply with this requirement, two adjacent pipes, denoted as spigot pipe and socket pipe in Figure 2, together with the locking bars and the rubber sealing are discretized by three-dimensional finite elements with quadratic shape functions. Because of two-fold symmetry only a quarter of the joint is discretized (Figure 3 ) and the respective symmetry conditions are applied as boundary conditions at the vertical faces of the FE-mesh.

The employed ductile cast iron is modelled as an elastic-plastic material of the von Mises-type with isotropic strain hardening. The Young's modulus is given as $154050 \mathrm{~N} / \mathrm{mm}^{2}$, the yield stress at $0.2 \%$ permanent strain and the tensile strength amount to $300 \mathrm{~N} / \mathrm{mm}^{2}$ and $620 \mathrm{~N} / \mathrm{mm}^{2}$, respectively, and the strain at rupture is about $7 \%$. The given material properties refer to the respective test conducted on the joint DN $200 \mathrm{~K} 13$, which is described in the next section. In particular, the measured tensile strength exceeds the respective code requirement [5].

For describing the material behaviour of the rubber sealing the constitutive model by Mooney-Rivlin is employed. The latter is sufficiently accurate, because the strains in the rubber sealing do not exceed the limitations of this constitutive model. Contact between the pipes and the locking bars as well as between the pipes and the rubber sealing is taken into account by Coulomb-type friction laws. The complete 3D FE-model for the prototype DN200 K13 consists of about 1.2 Mio. degrees of freedom. 


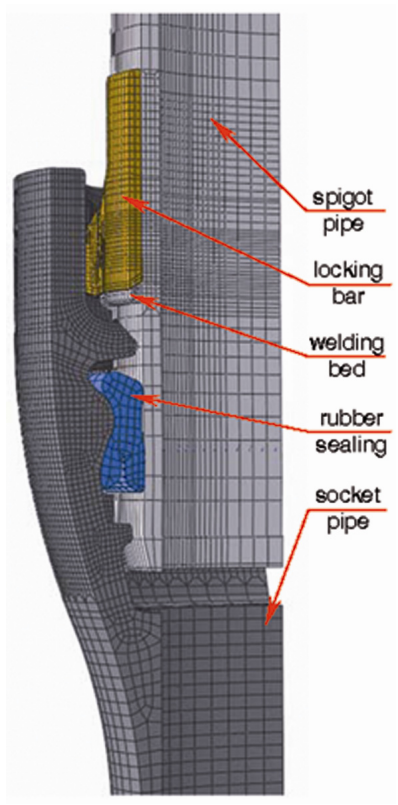

Figure 3: $\quad$ 3D FE-model of a quarter of the joint.

In the first step of the FE-analysis the installation of the rubber sealing is simulated. In this context, contact between the rubber sealing and the pipes has to be taken into account. The deformed configuration of the rubber sealing after installation, which was obtained from a simpler FE-simulation assuming axial symmetry, was integrated into the 3D FE-model.

In the second step the installation of the locking bars is simulated. In this context, contact between the locking bars and the pipes has to be taken into account.

Subsequently, the internal pressure is increased step by step. Figure 4 shows the predicted deformations of the joint (magnifying the displacements by a factor of 10) for pressure levels of 185 bar and 225 bar. According to Figure 4, the locking bar is clamped between the welding bed of the spigot pipe and the socket pipe. Failure of convergence of the numerical simulation occurs at an internal pressure exceeding 225 bar. Hence, the internal pressure of 225 bar indicates the ultimate load of the joint. At this pressure level, large domains of the joint are characterized by plastic material behaviour, in particular, the region in the vicinity of the contact area between the locking bar and the socket pipe and the region in the vicinity of the contact area between the welding bed of the spigot pipe and the locking bar. 

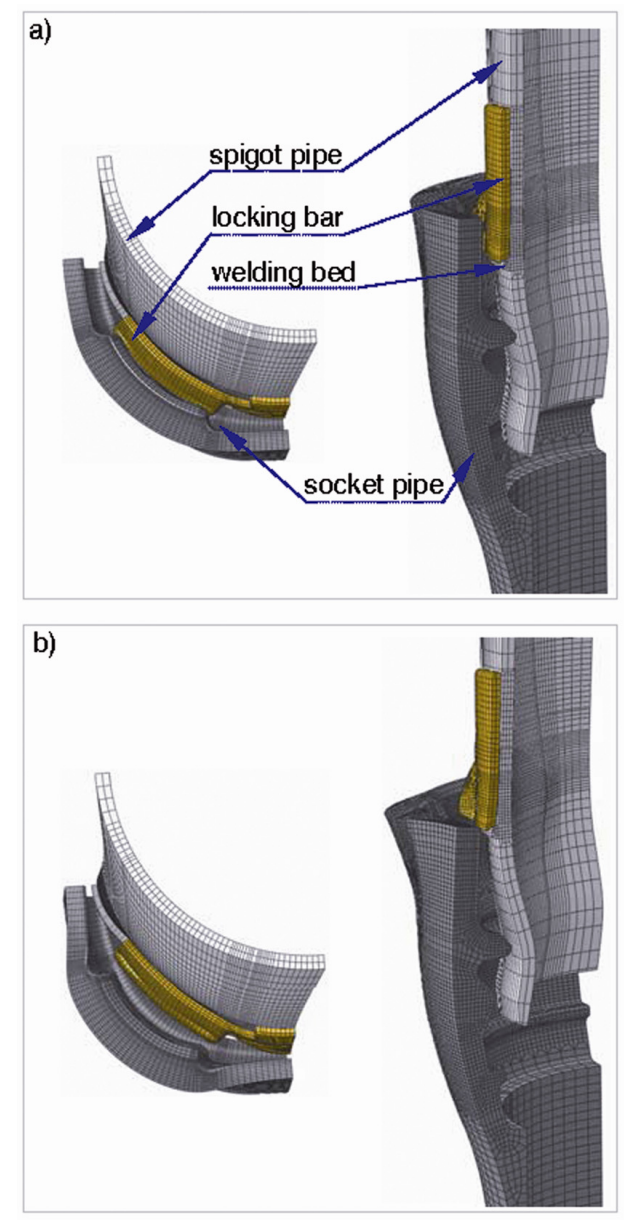

Figure 4: Predicted deformations of the joint at an internal pressure of a) 185 bar and b) 225 bar (displayed displacements are magnified by a factor of 10).

\section{Experimental investigation}

The test set-up for the experimental investigation, shown in Figure 5, was selected complying with the respective code requirements of the European standard ÖNORM EN 545 [5]. Two connected pipe segments of $1 \mathrm{~m}$ length each were supported by saddles. The latter were mounted on trolleys for reducing restraint effects due to relative displacements of the pipe segments at the joint, caused by the increasing internal pressure during the test. 


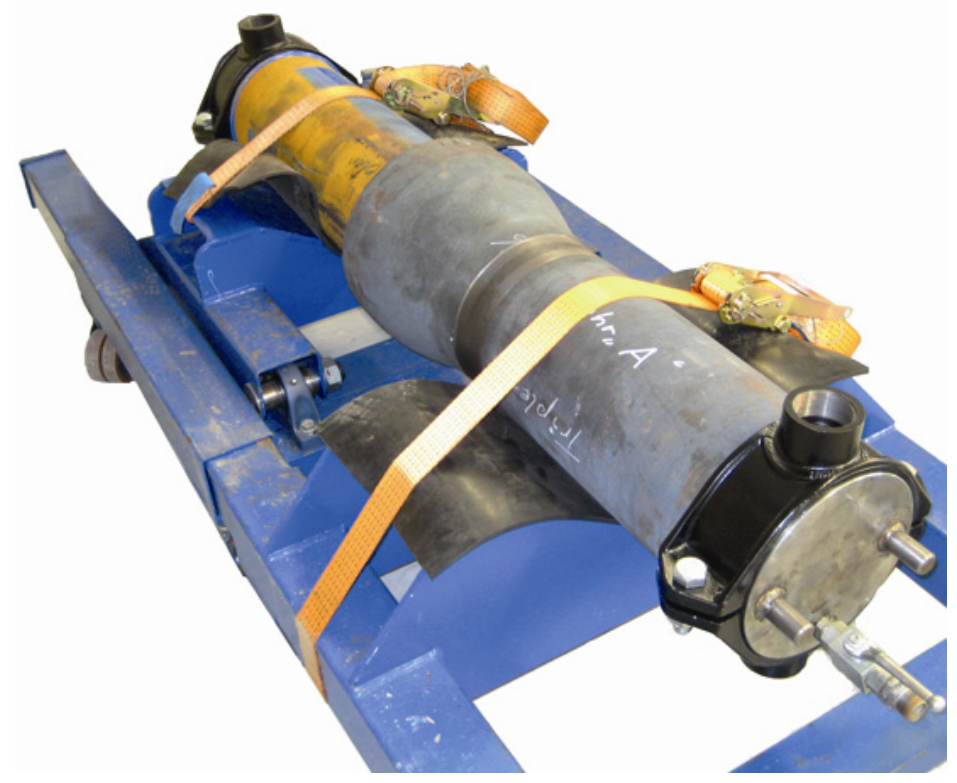

Figure 5: Test set-up.

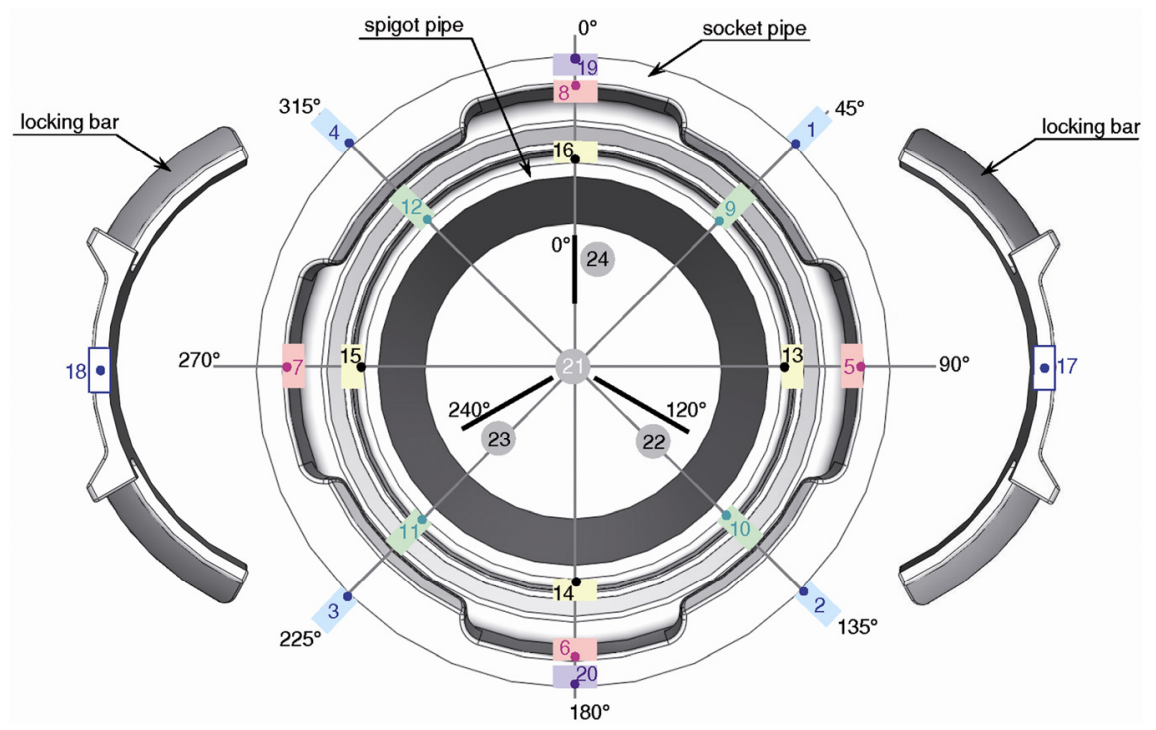

Figure 6: Arrangement of strain gauges and displacement transducers at the joint. 
In order to monitor the structural behaviour of the joint with increasing internal pressure the pipe segments and the locking bars are equipped with strain gauges. Figure 6 shows the arrangement of the strain gauges applied at the socket pipe (measurement points no. 1 to 8), applied at the spigot pipe (measurement points no. 9 to 16) and applied at the two locking bars (measurement points no. 17 and 18), as well as the pressure transducer (measurement point no. 21) and three displacement transducers (measurement points no. 22 to 24). The latter are employed for measuring axial displacements of the socket pipe relative to the spigot pipe, thereby indicating a potential relative rotation of the pipe segments at the joint due to the application of the internal pressure during the test.

In the experimental investigation the internal pressure was increased up to 155 bar in three steps. This pressure was kept constant for one hour and, subsequently, it was increased further up to 185 bar. This pressure was maintained for two minutes, before the sample was unloaded. Failure of an air valve prevented the further increase of the pressure up to failure.

Figure 7 exemplarily shows the circumferential strains measured at the inner surface of the socket pipe at measurement points 5 to 8 (MP5 to MP8).

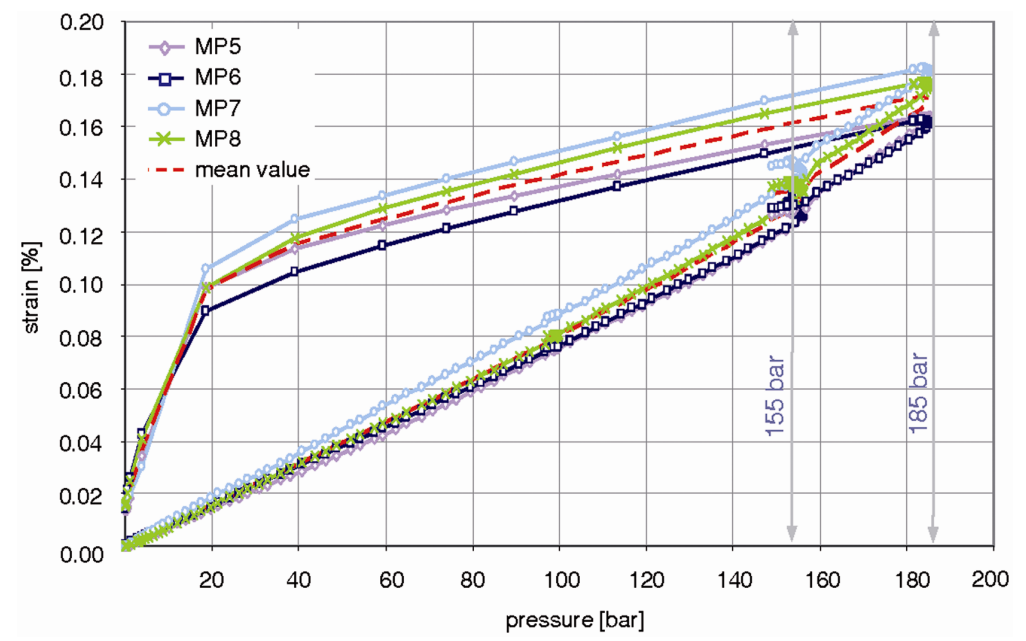

Figure 7: Measured circumferential strains at the inner surface of the socket pipe in terms of the applied pressure.

As can be seen from Figure 7, the differences of the measured circumferential strains at points MP5 to MP8 are relatively small. Hence, the measurement data confirm the desired uniform straining of the joint along its circumference. The diagram in Figure 7 shows permanent strains after complete unloading, which can be attributed to plastic material behaviour of the pipe segments at internal pressures, exceeding the design pressure of 100 bar considerably, and to friction forces and keying of the pipe segments. 
In addition to the described experimental investigation with coaxial arrangement of the pipe segments, the same samples were used to carry out an experiment considering an intended kink of the axes of the two pipe segments of $4.8^{\circ}$ at the joint.

\section{Comparison of experimental and computed results}

In order to assess the preliminary design of the joint the measured and the computed strains are compared. Here, for brevity, the comparison is restricted to the circumferential strains at the inner surface of the socket pipe at the pressure level of 185 bar. Figure 8 shows the respective computed strains for one quarter of the socket pipe segment. The two ellipses indicate the positions of the strain gauges MP 5 to MP 8 (see Figure 6). Hence, the mean value of the measured circumferential strains at the internal pressure of 185 bar, shown in Figure 7, can be compared with the computed strains at the locations, indicated by the ellipses in Figure 8. The distribution of the circumferential strains within the domain, enclosed by the ellipses, is characterized by a large gradient with a maximum value of $0.125 \%$. Comparison of the mean value of the measured circumferential strains of about $0.17 \%$ (see the dashed line in Figure 7 ) with the computed ones shows satisfactory agreement, taking into account that the thickness of the tested pipe segments is somewhat larger than the minimum thickness considered in the numerical simulation.
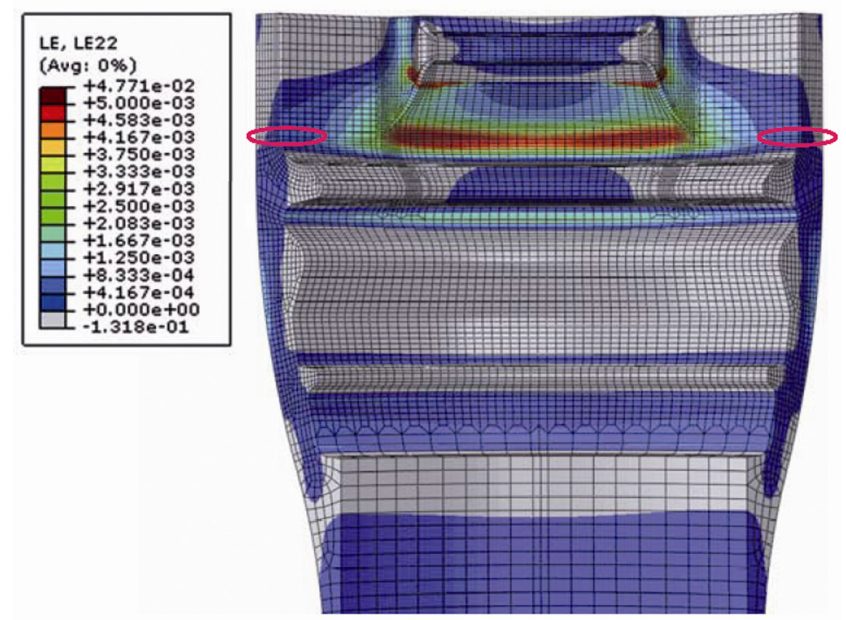

Figure 8: Computed circumferential strains at the inner surface of the socket pipe segment at an internal pressure of 185 bar. 


\section{Summary}

This paper focused on the development of pipe systems for high operating pressures, consisting of individual pipes, made of ductile cast iron, which are connected at the construction site by joints, assuring water tightness by a rubber sealing. Since the joints are critical parts of such pipelines, a fully threedimensional FE-model of a joint was developed for assessing the preliminary design of a joint by numerical simulations. It was employed for studying the load carrying behaviour of a joint up to failure. The numerical results, and, thus, the preliminary design, were evaluated by an experimental investigation on a prototype of a joint. In the test the structural behaviour was monitored by strain gauges and displacement transducers. Comparison of the computed and measured results and further numerical investigation of the impact of design modifications on the structural behaviour led to the final design of a joint.

\section{Acknowledgements}

Financial support of this applied research project by the Austrian Research Promotion Agency (FFG) is gratefully acknowledged. Furthermore, the work was supported by the Austrian Ministry of Science BMWF as part of the UniInfrastrukrurprogramm of the Forschungsplattform Scientific Computing at LFU Innsbruck.

\section{References}

[1] Titze, E., Duktile Gussrohre für Beschneiungsanlagen, Gussrohrtechnik, 37, pp. 13-17, 2003

[2] Titze, E., Extreme Belastungen - Planung und Bau einer Turbinenrohrleitung aus duktilem Gusseisen unter Berücksichtigung bruchmechanischer Bemessungsverfahren. Gussrohrtechnik, 32, pp. 58 ff, 1997

[3] Hofstetter, G., Lehar, H., Niederwanger, G., Design of pile-supported buried pipelines by a synthesis of FE ultimate load analyses and experimental investigations, Finite Element in Analysis and Design, 32, pp. 97-111, 1999.

[4] Lehar, H., Niederwanger, G., Hofstetter, G., FE ultimate load analyses of pile-supported pipelines - tackling uncertainty in a real design problem, in Analyzing Uncertainty in Civil Engineering, Eds.: Fellin, W., Lessmann, H., Oberguggenberger, M., Vieider, R., Springer-Verlag: Berlin, pp. 129-163, 2005.

[5] ÖNORM EN 545., Ductile iron pipes, fittings, accessories and their joints for water pipelines. Requirement ant test method, European Committee for Standardization (CEN), B-1050 Brüssel, 2007. 